\title{
Pediatric hypertension based on Japanese Society of Hypertension Guidelines (JSH 2019) with actual school blood pressure screening data in Japan
}

Toru Kikuchi, MD, PhD

Department of Pediatrics, Saitama Medical University, Saitama, Japan

Blood pressure (BP) in children and adolescents is associated with their growth. BP is most strongly associated with height during height gain and with degree of obesity after reaching final height. BP in childhood and adolescence is correlated with BP in adulthood. The pathophysiology of pediatric essential hypertension is associated with obesity, excess salt intake, and a low birth weight. The common causes of pediatric secondary hypertension are renal parenchymal and renovascular diseases. The significance of diagnosing pediatric hypertension involves detecting secondary hypertension and preventing organ damage due to hypertension as well as tracking essential hypertension in adulthood. Appropriate BP measurement procedures are required for diagnosing pediatric hypertension. The inflatable bladder of an appropriately sized cuff should exceed $40 \%$ of the arm circumference. BP measurements should be performed consecutively at least 3 times using an appropriately sized cuff. The diagnosis of hypertension requires that all $\mathrm{BP}$ values measured on 3 or more occasions be above the reference value. The criteria for pediatric hypertension are determined based on the distribution of BP in healthy children and adolescents, with values above the 95th percentile of normal representing hypertension. Japanese criteria define pediatric hypertension as $\geq 120 / 70 \mathrm{mmHg}$ for preschool children, $\geq 130 / 80 \mathrm{mmHg}$ for 1st-3rd graders, $\geq 135 / 80 \mathrm{mmHg}$ for 4 th- 6 th graders, $\geq 140 / 85$ $\mathrm{mmHg}$ for 7 th-9th grade boys, $\geq 135 / 80 \mathrm{mmHg}$ for 7 th-9th grade girls, and $\geq 140 / 85 \mathrm{mmHg}$ for senior high school boys and girls. The prevalence of Japanese pediatric hypertension was $0.9 \%$ based on proper measurement protocols. The basis of managing pediatric essential hypertension is healthy lifestyle modifications. Pharmacotherapy is indicated for persistent hypertension, symptomatic hypertension, secondary hypertension, the development of target organ damage, the presence of chronic kidney disease, and diabetes mellitus. Screening for pediatric hypertension is important; therefore, BP should be routinely measured in children and adolescents.

Key words: Child, Blood pressure, Growth, Birth weight, Obesity

\section{Key message}

The prevalence of Japanese pediatric hypertension is $0.9 \%$ based on proper measurement protocols. Hypertensive children tend to be hypertensive adults. Pediatric essential hypertension is characterized by an absence of symptoms, obesity, a family history of hypertension, and a low birth weight. The most common causes of pediatric secondary hypertension are renal parenchymal and renovascular diseases. Important factors controlling pediatric hypertension include healthy lifestyle modifications and pharmacotherapy.

\section{Introduction}

The prevalence of pediatric hypertension is much lower than that in adults. However, pediatricians must be aware of its associated problems because pediatric secondary hypertension requires urgent treatment. Pediatric essential hypertension should be managed to prevent organ damage and track adult hypertension. Here I briefly review the pathophysiology of pediatric hypertension and introduce its diagnosis and management according to the Japanese Society of Hypertension Guidelines for the Management of Hypertension (JSH 2019). ${ }^{1)}$

\section{Development of blood pressure from childhood to adulthood}

\section{Blood pressure and growth during childhood}

In children and adolescents, blood pressure (BP) increases physiologically as height increases. BP is also closely associated with obesity in childhood and adolescence. That is, BP in children and adolescents is correlated with age, height, and degree of obesity. Height is most strongly associated with BP during periods of height gain, whereas the degree of obesity shows the strongest association after one reaches their final height. ${ }^{2)}$

We longitudinally measured the BP, height, and weight of 78

Corresponding author: Toru Kikuchi, MD, PhD. Department of Pediatrics, Saitama Medical University, 38 Morohongo, Moroyama, Saitama, 3500495, Japan 凶Email: tkikuchi@saitama-med.ac.jp, https://orcid.org/0000-0001-8392-6148

Received: 10 July 2021, Revised: 27 October 2021, Accepted: 28 October 2021

This is an open-access article distributed under the terms of the Creative Commons Attribution Non-Commercial License (http://creativecommons.org/licenses/bync/4.0/) which permits unrestricted non-commercial use, distribution, and reproduction in any medium, provided the original work is properly cited. 


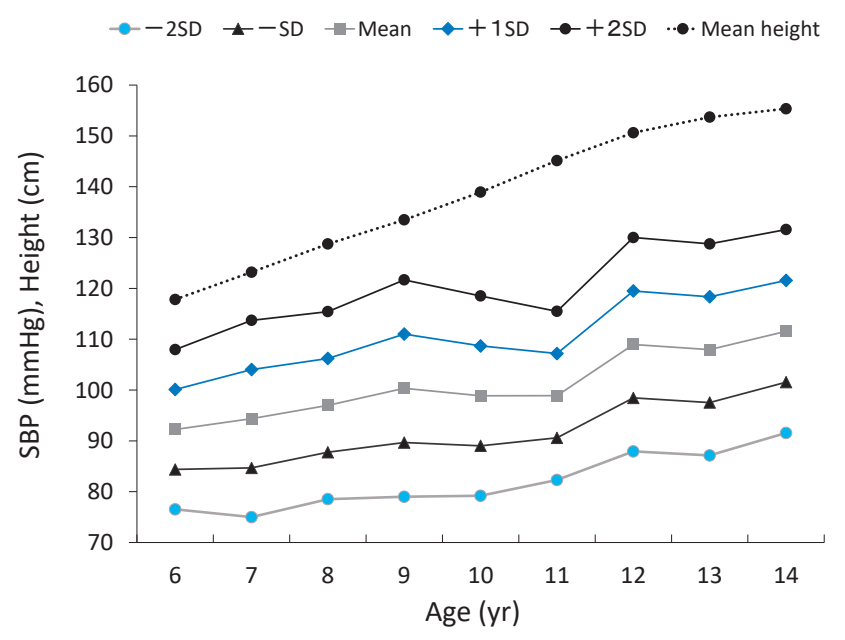

Fig. 1. Longitudinal changes in mean (SD) SBP in 78 Japanese girls. The SBP curve shows changes similar to the height curve. SBP, systolic blood pressure; SD, standard deviation

girls annually from 6 to 14 years of age in BP check-ups conducted at a school in Mitsuke City, Niigata Prefecture, Japan. The study was approved by the ethics committee of Saitama Medical University. The approval number was no. 840. Fig. 1 shows the longitudinal changes in systolic $\mathrm{BP}(\mathrm{SBP})$ and height among the participants. The SBP curve changed with the height curve. We performed simple regression analyses with SBP or diastolic BP (DBP) as the dependent variable and height standard deviation (SD) score or percent of overweight (POW) as the independent variable. The height SD score and POW were calculated using the following formulae:

Height SD score $=($ measured height - standard height $) /$ stand ard deviation

POW $(\%)=($ measured weight - standard weight $) /$ standard weight $\times 100$

These analyses revealed that SBP was positively correlated with height SD score until 11 years of age and subsequently correlated with POW but not with height SD score. Even in childhood, hypertension is a disorder that results from obesity. Therefore, reference values for $\mathrm{BP}$ in children and adolescents by age and height are needed.

\section{Tracking to adult hypertension}

$\mathrm{BP}$ in children and adolescents is correlated with $\mathrm{BP}$ in adulthood. That is, individuals with a high BP in childhood tend to have a high BP in adulthood. This phenomenon is called tracking of BP. The SBP values of 89 boys and 89 girls in 9th grade at school BP check-ups in Mitsuke City showed significant positive correlations with those in 1st grade with correlation coefficients of 0.345 and 0.480 , respectively. ${ }^{3)}$ According to the results of BP comparisons at junior high school age and after 20 years of age in Japan, 20.9\% of hypertensive junior high school students were still hypertensive after 20 years, whereas only 5.5\% of normotensive individuals became hypertensive. ${ }^{4)}$ In a study that re-examined college students after 8-26 years, hypertension was observed in $44.6 \%$ of the initially hypertensive group versus only $9.2 \%$ of the initially normotensive group. ${ }^{5)}$ Therefore, the early detection of pediatric hypertension and prevention from tracking to adult hypertension may reduce the life course burden associated with hypertension. $\left.{ }^{6}\right)$

\section{Pathophysiology of pediatric hypertension}

\section{Etiology of pediatric hypertension}

Essential hypertension in children and adolescents is characterized by the absence of symptoms, obesity, a family history of hypertension, and a low birth weight. Almost all cases of essential hypertension are of mild grade that develop after puberty. In terms of underlying mechanisms, essential hypertension in children and adolescents is associated with insulin resistance $\left.{ }^{7}\right)$ and excessive salt ingestion ${ }^{8}$ as reported for adults.

The most common causes of secondary hypertension in children and adolescents are renal parenchymal and renovascular diseases. Renal parenchymal disease includes kidney scarring associated with vesicoureteral reflux and chronic kidney disease (CKD) related to congenital renal/urinary tract abnormalities. Other causes of secondary hypertension in children and adolescents include cardiovascular disease, endocrine disease, and adverse drug events (ADEs). Secondary hypertension should be suspected in cases of hypertension at a younger age or higher BP.

A survey of pediatric secondary hypertension was performed in 2004 among members of the Japanese Society of Pediatric Hypertension. This survey resulted in 66 cases of secondary hypertension $^{9)}$ due to glomerulonephritis in 22 cases (32\%), renovascular hypertension in 14 cases $(21 \%)$, renal failure in 8 cases $(12 \%)$, congenital renal/urinary tract abnormalities in 8 cases (12\%), aortic coarctation in 4 cases (6\%), cerebrovascular disease in 2 cases (3\%), ADEs in 4 cases (6\%), and miscellaneous in 4 cases (6\%).

\section{Obesity and pediatric hypertension}

Obesity is the most frequent risk factor for essential hypertension in pediatric patients. Insulin resistance and hyperinsulinemia due to visceral fat accumulation in childhood obesity induce systolic hypertension with tachycardia. Hyperleptinemia is also associated with obesity-induced hypertension." Children and adolescents with moderate to severe obstructive sleep apnea are at increased risk of pediatric hypertension. ${ }^{10)}$ The prevalence of systolic hypertension in nonobese children and adolescents was $0.5 \%$ in 3,059 boys and $0.5 \%$ in 3,221 girls at a school health check-up in Mitsuke City, Japan. ${ }^{11)}$ However, the prevalence of systolic hypertension in obese boys and girls was 3.3\% and $5.0 \%$, respectively. Furthermore, the prevalence of systolic hypertension in mild, moderate, and severe obesity was $1.6 \%$, $4.2 \%$, and $8.3 \%$ in boys and $3.1 \%, 5.6 \%$, and $12.5 \%$ in girls, respectively (Table 1). ${ }^{11)}$

\section{Birth weight and pediatric hypertension}

The etiology of essential hypertension is explained by the 
Table 1. Mean and standard deviation of blood pressure, and prevalence of high normal blood pressure and hypertension according to JSH 2004 physique categories

\begin{tabular}{|c|c|c|c|c|c|c|c|}
\hline \multirow{2}{*}{ Variable } & \multirow{2}{*}{ No. } & \multicolumn{3}{|c|}{ Systolic blood pressure (mmHg) } & \multicolumn{3}{|c|}{ Diastolic blood pressure (mmHg) } \\
\hline & & Mean & High normal & Hypertension & Mean & High normal & Hypertension \\
\hline \multicolumn{8}{|l|}{ Boys $(n=3,059)$} \\
\hline Emaciated & 76 & $101 \pm 14$ & $3(3.9)$ & $0(0)$ & $54 \pm 9$ & $2(2.6)$ & $0(0)$ \\
\hline Lean & 2,588 & $101 \pm 12$ & $42(1.6)$ & $14(0.5)$ & $52 \pm 8$ & $42(1.6)$ & $5(0.2)$ \\
\hline Obese & 395 & $110 \pm 14$ & $39(9.9)$ & $13(3.3)$ & $55 \pm 8$ & $11(2.8)$ & $1(0.3)$ \\
\hline Mildly obese & 193 & $107 \pm 13$ & $13(6.7)$ & $3(1.6)$ & $53 \pm 8$ & $4(2.1)$ & $0(0)$ \\
\hline Moderately obese & 166 & $111 \pm 14$ & $22(13.3)$ & $7(4.2)$ & $56 \pm 8$ & $7(4.2)$ & $1(0.6)$ \\
\hline Severely obese & 36 & $114 \pm 15$ & $4(11.1)$ & $3(8.3)$ & $55 \pm 7$ & $0(0)$ & $0(0)$ \\
\hline All boys & 3,059 & $102 \pm 13$ & $84(2.7)$ & $27(0.9)$ & $52 \pm 8$ & $55(1.8)$ & $6(0.2)$ \\
\hline \multicolumn{8}{|l|}{ Girls $(n=3,221)$} \\
\hline Emaciated & 109 & $101 \pm 12$ & $3(2.8)$ & $0(0)$ & $55 \pm 9$ & $10(9.2)$ & $1(0.9)$ \\
\hline Lean & 2,812 & $101 \pm 12$ & $66(2.3)$ & $14(0.5)$ & $52 \pm 8$ & $64(2.3)$ & $5(0.2)$ \\
\hline Obese & 300 & $107 \pm 15$ & $29(9.7)$ & $15(5)$ & $55 \pm 8$ & $9(3.0)$ & $4(1.3)$ \\
\hline Mildly obese & 161 & $106 \pm 13$ & $9(5.6)$ & $5(3.1)$ & $54 \pm 8$ & $3(1.9)$ & $2(1.2)$ \\
\hline Moderately obese & 107 & $107 \pm 15$ & $11(10.3)$ & $6(5.6)$ & $54 \pm 9$ & $3(2.8)$ & $2(1.9)$ \\
\hline Severely obese & 32 & $117 \pm 17$ & $9(28.1)$ & $4(12.5)$ & $60 \pm 7$ & $3(9.4)$ & $0(0)$ \\
\hline All girls & 3,221 & $101 \pm 12$ & $98(3.0)$ & $29(0.9)$ & $53 \pm 8$ & $83(2.6)$ & $10(0.3)$ \\
\hline
\end{tabular}

Values are presented as mean \pm standard deviation or number (\%).

Emaciated: percent overweight $\leq-20 \%$, lean: $-20 \%<$ percent overweight $<+20 \%$, obese: $+20 \% \leq$ percent overweight, mildly obese: $+20 \% \leq$ percent overweight $<+30 \%$, moderately obese: $+30 \% \leq$ percent overweight $<+50 \%$, severely obese: $+50 \%$ spercent overweight.

concept of developmental origins of health and disease. ${ }^{12)}$ In a study of Japanese children, BP at 3 years of age was higher in children with a lower birth weight and a higher current body weight. ${ }^{13)}$ Moreover, in a follow-up study of 4,626 Japanese individuals from birth until 20 years of age, a lower birth weight and lower rate of height increase from 3 to 20 years old were independently associated with elevated BP and serum cholesterol levels at 20 years of age. ${ }^{14)}$ A study of severely obese Japanese children reported that those with a lower birth weight tended to show pediatric metabolic syndrome with hypertension. ${ }^{15)}$ The fetus prioritizes the brain for the supply of glucose, so if the mother is malnourished, other fetal organs such as the liver, muscles, and kidneys will be deprived of sufficient glucose. As a result, low birth weight infants have insulin resistance and a lower number of nephrons. ${ }^{16,17)}$ Infants who show an excess weight gain after birth are more likely to become obese children with hypertension. ${ }^{15)}$ Thus, low birth weight is a risk factor for essential hypertension in pediatric patients.

\section{Diagnosis of pediatric hypertension}

\section{BP measurement in children}

Appropriate BP measurement procedures are required for the diagnosis of pediatric hypertension. The right brachial BP should be measured in a sitting position as in adults. In small children, BP should be measured with the child in a seated position on the lap of a parent. An appropriately sized cuff for a child is required to ensure BP measurement accuracy. Cuffs are commercially available at $7 \mathrm{~cm}$ wide for children 3-6 years old, $9 \mathrm{~cm}$ for those 6-9 years old, and $12 \mathrm{~cm}$ (adult size) for $\geq 9$ years. However, the cuff should be matched to the circum. ference of the upper arm rather than age. Appropriate cuff conditions were as follows: (1) inflatable bladder width in the cuff exceeding $40 \%$ of the arm's circumference at the point midway between the olecranon and acromion; and (2) cuff width $>80 \%$ of the length of the upper arm. BP measurement by auscultation is desirable, but the use of an oscillometric method is also permitted. In the auscultation method, the rate of cuff deflation is $2-3 \mathrm{mmHg}$ per beat or second, the BP at the start of the first Korotkoff sound is considered the SBP, while that at the fifth Korotkoff sound is considered the DBP. ${ }^{1)}$ Since children often cannot remain still for sufficiently long periods, using an electronic sphygmomanometer by the oscillometric method may be warranted. DBP values tend to be lower when measured by this method than when measured by auscultation. BP should be measured 3 or more times at intervals of $1-2$ minutes in the examination room. JSH 2019 notes that the average of 2 stable values from these measurements should be considered the measurement result. ${ }^{1)}$ Stable values were defined as those with a difference of less than $5 \mathrm{mmHg}$ between the 2 measurements. However, some epidemiological studies have analyzed the last measured value. We measured BP 3 consecutive times using a Dinamap automatic sphygmomanometer (Critikon Inc., Tampa, FL, USA) with an appropriate cuff in a BP check-up of school children in Mitsuke City and compared each BP value. As a result, the first measurement was significantly higher and the third was significantly lower (Table 2). ${ }^{18)}$ 
Table 2. Comparison of 1st, 2nd, and 3rd measurements of blood pressure in school children

\begin{tabular}{|c|c|c|c|c|c|}
\hline \multirow{2}{*}{ Variable } & \multirow{2}{*}{ 1st measurement } & \multirow{2}{*}{ 2nd measurement } & \multirow{2}{*}{ 3rd measurement } & \multicolumn{2}{|c|}{$P$ value } \\
\hline & & & & Bartlett test & Friedmann test \\
\hline \multicolumn{6}{|l|}{ Boys $(n=644)$} \\
\hline \multicolumn{6}{|l|}{ Systolic blood pressure } \\
\hline All boys ( $\mathrm{n}=644)$ & $106 \pm 14$ & $103 \pm 14$ & $102 \pm 13$ & $<0.0001$ & $<0.0001$ \\
\hline 1st-3rd graders $(n=277)$ & $98 \pm 11$ & $95 \pm 11$ & $94 \pm 11$ & $<0.0001$ & $<0.0001$ \\
\hline 4th-6th graders $(n=211)$ & $106 \pm 10$ & $103 \pm 10$ & $101 \pm 10$ & $<0.0001$ & $<0.0001$ \\
\hline 7th-9th graders $(n=206)$ & $115 \pm 14$ & $113 \pm 14$ & $111 \pm 12$ & $<0.0001$ & $<0.0001$ \\
\hline \multicolumn{6}{|l|}{ Diastolic blood pressure } \\
\hline All boys $(n=644)$ & $54 \pm 8$ & $53 \pm 8$ & $51 \pm 8$ & $<0.0001$ & $<0.0001$ \\
\hline 1 st-3rd graders $(n=277)$ & $52 \pm 8$ & $50 \pm 11$ & $49 \pm 8$ & $<0.0001$ & $<0.0001$ \\
\hline 4th-6th graders $(n=211)$ & $54 \pm 7$ & $53 \pm 7$ & $51 \pm 7$ & $<0.0001$ & $<0.0001$ \\
\hline 7th-9th graders $(n=206)$ & $57 \pm 8$ & $55 \pm 7$ & $54 \pm 7$ & $<0.0001$ & $<0.0001$ \\
\hline \multicolumn{6}{|l|}{ Girls (n=652) } \\
\hline \multicolumn{6}{|l|}{ Systolic blood pressure } \\
\hline All girls $(n=652)$ & $105 \pm 13$ & $103 \pm 12$ & $101 \pm 12$ & $<0.0001$ & $<0.0001$ \\
\hline 1 st-3rd graders $(n=220)$ & $98 \pm 7$ & $95 \pm 9$ & $93 \pm 9$ & $<0.0001$ & $<0.0001$ \\
\hline 4th-6th graders $(n=228)$ & $107 \pm 12$ & $104 \pm 11$ & $102 \pm 10$ & $<0.0001$ & $<0.0001$ \\
\hline 7th-9th graders $(n=204)$ & $112 \pm 14$ & $110 \pm 12$ & $109 \pm 11$ & $<0.0001$ & $<0.0001$ \\
\hline \multicolumn{6}{|l|}{ Diastolic blood pressure } \\
\hline All girls $(n=652)$ & $54 \pm 8$ & $53 \pm 8$ & $52 \pm 8$ & $<0.0001$ & $<0.0001$ \\
\hline 1 st-3rd graders $(n=220)$ & $51 \pm 7$ & $50 \pm 7$ & $49 \pm 8$ & $<0.0001$ & $<0.0001$ \\
\hline 4th-6th graders $(n=228)$ & $55 \pm 8$ & $54 \pm 7$ & $52 \pm 8$ & $<0.0001$ & $<0.0001$ \\
\hline 7th-9th graders $(n=204)$ & $57 \pm 9$ & $55 \pm 9$ & $54 \pm 8$ & $<0.0001$ & $<0.0001$ \\
\hline
\end{tabular}

Values are presented as mean \pm standard deviation.

Boldface indicates a statistically significant difference with $P<0.05$.

\section{Criteria for pediatric hypertension}

The criteria for defining pediatric hypertension differ from those for adults. In adults, the criteria for hypertension are set as risk factors for outcomes such as cardiovascular disease. However, the criteria for pediatric hypertension are determined based on the distribution of BP among healthy children and adolescents because outcome data are not available for them. The 90th and 95th percentiles of the normal distributions are often set as reference ranges for high normal BP and hypertension, respectively. As BP is correlated with age and height in healthy children and adolescents, the criteria for pediatric hypertension should logically be determined by sex, age, and height. The guidelines for the screening and management of high BP in children and adolescents by the American Academy of Pediatrics (AAP2017) describe the 90th and 95th percentiles of SBP and DBP in each age group according to the 5th, 10th, 25th, 50th, 75th, 90th, and 95th percentiles of height. The AAP2017 guidelines define 728 criteria for pediatric hypertension before 13 years of age by sex, age, and height, ${ }^{19)}$ but such a high num. ber of criteria limits the speed and ease of use for clinicians. One study reported that the use of simple diagnostic criteria of $\geq 120 / 80 \mathrm{mmHg}$ for $6-11$ years old and $\geq 130 / 85 \mathrm{mmHg}$ for 12-17 years old could be useful for screening for adult cardiovascular disease risk. ${ }^{20)}$

In Japan, few reports have examined reference values for BP among children and adolescents. One study reported that reference values for SBP and DBP by grade and height percentile for each sex were analyzed using BP data obtained from medical check-ups at elementary and junior high schools in Mitsuke City, Japan, during the 10-year period of 1999-2008. The study included 5,805 boys and 5,970 girls. An automatic BP monitor (Dinamap model 8104; Critikon Inc.) was used to measure BP using an appropriate cuff size. BP was measured at the right upper arm, and the third measurement was performed. Table 3 shows the mean, 90th, and 95th percentiles of BP by sex and grade in this study. Table 3 shows the correlation coefficients and linear regression analyses of $\mathrm{BP}$ on height $\mathrm{SD}$ score and mean $\mathrm{BP}$ levels by grade according to height percentile. The difference between the SBP values at the 90th and 10th percentiles of height during the pubertal height spurt was approximately $8 \mathrm{mmHg}$. The difference at the lower grades was approximately $5 \mathrm{mmHg}$. A small difference in DBP was observed.

Table 4 shows the criteria for pediatric hypertension as defined in the JSH 2019. ${ }^{1)}$ These criteria were established based on about 40,000 BP measurement data points obtained using an automatic BP meter by oscillometric methods at the Tokyo Health Service Association. The 90th and 95th percentile values estimated from these data are defined as high normal BP and hypertension, respectively. The school BP check-up data in Mitsuke City were not adopted as a reference for hypertension in Japanese children because they do not represent Japan as a whole.

The diagnosis of hypertension requires that all $\mathrm{BP}$ values measured on 3 or more occasions be above the reference value. According to a meta-analysis of the prevalence of pediatric 
Table 3. Mean $\pm \mathrm{SD}, 90$ th, and 95th percentiles of BP, correlation coefficient between BP and height SD score, and estimated mean $\mathrm{BP}$ values of each height percentile according to sex and grade

\begin{tabular}{|c|c|c|c|c|c|c|c|c|c|c|c|}
\hline \multirow[t]{2}{*}{ Variable } & \multirow[t]{2}{*}{ No. } & \multicolumn{3}{|c|}{ Blood pressure (mmHg) } & \multicolumn{2}{|c|}{$\begin{array}{l}\text { Simple regression } \\
\text { coefficient between } \mathrm{BP} \\
\text { and height SD score }\end{array}$} & \multicolumn{5}{|c|}{$\begin{array}{l}\text { Estimated BP values according to each height } \\
\text { percentile }(\mathrm{mmHg})\end{array}$} \\
\hline & & Mean \pm SD & 90th & 95th & $r$ & $P$ value & 10th & 25th & 50th & 75th & 90th \\
\hline \multicolumn{12}{|c|}{ Boys $(n=5,805)$} \\
\hline \multicolumn{12}{|c|}{ Systolic blood pressure } \\
\hline $1 s t$ & 642 & $91 \pm 9$ & 103 & 107 & 0.193 & $<0.0001$ & 89 & 90 & 91 & 93 & 94 \\
\hline 2nd & 649 & $93 \pm 9$ & 105 & 108 & 0.337 & $<0.0001$ & 89 & 91 & 93 & 95 & 97 \\
\hline $3 r d$ & 670 & $94 \pm 10$ & 106 & 110 & 0.286 & $<0.0001$ & 90 & 92 & 94 & 95 & 97 \\
\hline 4th & 685 & $98 \pm 10$ & 111 & 115 & 0.252 & $<0.0001$ & 95 & 97 & 98 & 100 & 101 \\
\hline 5th & 686 & $98 \pm 10$ & 112 & 116 & 0.290 & $<0.0001$ & 94 & 96 & 98 & 100 & 102 \\
\hline 6th & 688 & $101 \pm 11$ & 115 & 119 & 0.299 & $<0.0001$ & 97 & 99 & 101 & 103 & 105 \\
\hline 7th & 584 & $110 \pm 11$ & 125 & 129 & 0.242 & $<0.0001$ & 106 & 108 & 110 & 112 & 113 \\
\hline 8th & 591 & $112 \pm 11$ & 126 & 130 & 0.176 & $<0.0001$ & 109 & 110 & 111 & 113 & 114 \\
\hline 9th & 610 & $115 \pm 11$ & 129 & 133 & 0.125 & 0.0020 & 113 & 114 & 114 & 115 & 116 \\
\hline \multicolumn{12}{|c|}{ Diastolic blood pressure } \\
\hline $1 s t$ & 642 & $49 \pm 7$ & 58 & 61 & 0.126 & 0.0013 & 48 & 48 & 49 & 50 & 50 \\
\hline 2nd & 649 & $49 \pm 7$ & 59 & 61 & 0.165 & $<0.0001$ & 48 & 48 & 49 & 50 & 51 \\
\hline $3 r d$ & 670 & $49 \pm 7$ & 59 & 61 & 0.198 & $<0.0001$ & 47 & 48 & 49 & 50 & 51 \\
\hline 4th & 685 & $51 \pm 7$ & 60 & 63 & 0.130 & 0.0007 & 50 & 51 & 51 & 52 & 52 \\
\hline 5th & 686 & $51 \pm 7$ & 60 & 63 & 0.144 & 0.0001 & 49 & 50 & 50 & 51 & 52 \\
\hline 6th & 688 & $51 \pm 7$ & 60 & 63 & 0.108 & 0.0045 & 50 & 50 & 51 & 51 & 52 \\
\hline 7th & 584 & $56 \pm 8$ & 66 & 69 & 0.029 & 0.4847 & 55 & 56 & 56 & 56 & 56 \\
\hline 8th & 591 & $55 \pm 8$ & 66 & 69 & 0.114 & 0.0056 & 54 & 55 & 55 & 56 & 56 \\
\hline 9th & 610 & $57 \pm 8$ & 67 & 70 & 0.095 & 0.0187 & 56 & 56 & 57 & 57 & 58 \\
\hline \multicolumn{12}{|c|}{ Girls $(n=5,970)$} \\
\hline \multicolumn{12}{|c|}{ Systolic blood pressure } \\
\hline 1st & 635 & $92 \pm 9$ & 103 & 107 & 0.248 & $<0.0001$ & 88 & 90 & 91 & 93 & 94 \\
\hline 2nd & 649 & $93 \pm 9$ & 104 & 107 & 0.250 & $<0.0001$ & 90 & 91 & 92 & 94 & 95 \\
\hline $3 r d$ & 664 & $94 \pm 9$ & 106 & 109 & 0.242 & $<0.0001$ & 92 & 93 & 94 & 96 & 97 \\
\hline 4th & 684 & $99 \pm 10$ & 112 & 116 & 0.328 & $<0.0001$ & 95 & 97 & 99 & 101 & 103 \\
\hline 5th & 711 & $99 \pm 10$ & 113 & 117 & 0.290 & $<0.0001$ & 95 & 97 & 99 & 101 & 103 \\
\hline 6th & 731 & $101 \pm 10$ & 115 & 118 & 0.279 & $<0.0001$ & 98 & 99 & 101 & 103 & 105 \\
\hline 7th & 615 & $110 \pm 11$ & 124 & 128 & 0.170 & $<0.0001$ & 107 & 108 & 110 & 111 & 112 \\
\hline 8th & 641 & $108 \pm 11$ & 122 & 126 & 0.070 & 0.0787 & 107 & 108 & 108 & 109 & 109 \\
\hline 9th & 640 & $110 \pm 11$ & 124 & 128 & 0.009 & 0.8174 & 109 & 109 & 110 & 110 & 110 \\
\hline \multicolumn{12}{|c|}{ Diastolic blood pressure } \\
\hline $1 s t$ & 635 & $49 \pm 7$ & 58 & 61 & 0.075 & 0.0575 & 48 & 48 & 49 & 49 & 50 \\
\hline 2nd & 649 & $49 \pm 7$ & 58 & 60 & 0.101 & 0.0102 & 49 & 49 & 49 & 50 & 50 \\
\hline $3 r d$ & 664 & $49 \pm 6$ & 57 & 60 & 0.110 & 0.0045 & 48 & 49 & 49 & 50 & 50 \\
\hline 4th & 684 & $52 \pm 7$ & 61 & 63 & 0.145 & 0.0001 & 50 & 51 & 52 & 52 & 53 \\
\hline 5th & 711 & $51 \pm 7$ & 61 & 63 & 0.151 & $<0.0001$ & 49 & 50 & 51 & 52 & 52 \\
\hline 6th & 731 & $51 \pm 7$ & 61 & 63 & 0.147 & $<0.0001$ & 50 & 51 & 51 & 52 & 53 \\
\hline 7th & 615 & $57 \pm 8$ & 68 & 71 & 0.111 & 0.0058 & 56 & 56 & 57 & 58 & 58 \\
\hline 8th & 641 & $56 \pm 8$ & 67 & 70 & 0.067 & 0.0924 & 56 & 56 & 56 & 57 & 57 \\
\hline 9th & 640 & $58 \pm 9$ & 69 & 72 & -0.006 & 0.8801 & 58 & 58 & 58 & 58 & 58 \\
\hline
\end{tabular}

$\mathrm{SD}$, standard deviation; BP, blood pressure.

Boldface indicates a statistically significant difference with $P<0.05$.

hypertension, $12.1 \%$ of children were diagnosed with hypertension on a single occasion, $5.6 \%$ on 2 occasions, and $2.7 \%$ on 3 occasions. ${ }^{21)}$ Thus, confirming hypertension on 3 or more occasions is important.

\section{Prevalence of pediatric hypertension in Japan}

We screened for pediatric hypertension in 6,280 healthy school children at school BP check-ups in Mitsuke City, Japan. The study was approved by the ethics committee of Saitama Medical University (approval no. 840). Pediatric hypertension 
was detected in $0 \%-4.4 \%$ of each grade and in $0.9 \%$ of healthy children. The prevalence of pediatric hypertension increased with increasing grade (Table 5). A meta-analysis of epidemiological studies on pediatric hypertension in the United States,

Table 4. Japanese criteria for pediatric hypertension as defined by the JSH

\begin{tabular}{|c|c|c|c|c|}
\hline \multirow{2}{*}{ Variable } & \multicolumn{2}{|c|}{$\begin{array}{l}\text { Systolic blood pressure } \\
(\mathrm{mmHg})\end{array}$} & \multicolumn{2}{|c|}{$\begin{array}{c}\text { Diastolic blood pressure } \\
(\mathrm{mmHg})\end{array}$} \\
\hline & Hypertension & $\begin{array}{l}\text { High } \\
\text { normal }\end{array}$ & Hypertension & $\begin{array}{l}\text { High } \\
\text { normal }\end{array}$ \\
\hline Preschool & $\geq 120$ & - & $\geq 70$ & - \\
\hline \multicolumn{5}{|l|}{ Elementary school } \\
\hline 1st-3rd graders & $\geq 130$ & $\geq 120$ & $\geq 80$ & $\geq 70$ \\
\hline 4th-6th graders & $\geq 135$ & $\geq 125$ & $\geq 80$ & $\geq 70$ \\
\hline \multicolumn{5}{|l|}{ Junior high school } \\
\hline Boys & $\geq 140$ & $\geq 130$ & $\geq 85$ & $\geq 70$ \\
\hline Girls & $\geq 135$ & $\geq 125$ & $\geq 80$ & $\geq 70$ \\
\hline Senior high school & $\geq 140$ & $\geq 130$ & $\geq 85$ & $\geq 75$ \\
\hline
\end{tabular}

$\mathrm{JSH}$, The Japanese Society of Hypertension Guidelines for the Management of Hypertension.

Hypertension is defined in JSH 2000, 2004, 2009, 2014, and 2019. High normal is defined in JSH 2000 and 2004.

Table 5. Prevalence of high normal blood pressure and hypertension according to JSH 2004 in each grade of Japanese school children

\begin{tabular}{|c|c|c|c|c|c|}
\hline \multirow{2}{*}{ Variable } & \multirow{2}{*}{ No. } & \multicolumn{2}{|c|}{ Systolic blood pressure (mmHg) } & \multicolumn{2}{|c|}{ Diastolic blood pressure (mmHg) } \\
\hline & & High normal & Hypertension & High normal & Hypertension \\
\hline \multicolumn{6}{|l|}{ Boys $(n=3,059)$} \\
\hline 1st graders & 344 & $2(0.6)$ & $0(0)$ & $2(0.6)$ & $2(0.6)$ \\
\hline 2 nd graders & 347 & $3(0.9)$ & $1(0.3)$ & $3(0.9)$ & $1(0.3)$ \\
\hline 3rd grades & 363 & $3(0.8)$ & $1(0.3)$ & $4(1.1)$ & $1(0.3)$ \\
\hline $1 \mathrm{st}-3 \mathrm{rd}$ graders & 1,054 & $8(0.8)$ & $2(0.2)$ & $9(0.9)$ & $4(0.4)$ \\
\hline 4 th graders & 368 & $4(1.1)$ & $0(0)$ & $2(0.5)$ & $0(0)$ \\
\hline 5th graders & 378 & $9(2.4)$ & $0(0)$ & $8(2.1)$ & $0(0)$ \\
\hline 6 th graders & 356 & $7(2.0)$ & $1(0.3)$ & $1(0.3)$ & $0(0)$ \\
\hline 4th-6th graders & 1,102 & $20(1.8)$ & $1(0.1)$ & $11(1)$ & $0(0)$ \\
\hline 7th graders & 299 & $11(3.7)$ & $4(1.3)$ & $11(3.7)$ & $2(0.7)$ \\
\hline 8th graders & 298 & $10(3.4)$ & $13(4.4)$ & $9(3.0)$ & $0(0)$ \\
\hline 9th graders & 306 & $35(11.4)$ & $7(2.3)$ & $15(4.9)$ & $0(0)$ \\
\hline 7th-9th graders & 903 & $56(6.2)$ & $24(2.7)$ & $35(3.9)$ & $2(0.2)$ \\
\hline All boys & 3,059 & $84(2.7)$ & $27(0.9)$ & $55(1.8)$ & $6(0.2)$ \\
\hline \multicolumn{6}{|l|}{ Girls (n=3,221) } \\
\hline 1st graders & 372 & $2(0.5)$ & $0(0)$ & $0(0)$ & $0(0)$ \\
\hline 2nd graders & 371 & $2(0.5)$ & $0(0)$ & $0(0)$ & $0(0)$ \\
\hline 3rd grades & 369 & $1(0.3)$ & $0(0)$ & $0(0)$ & $0(0)$ \\
\hline $1 \mathrm{st}-3 \mathrm{rd}$ graders & 1,112 & $5(0.4)$ & $0(0)$ & $0(0)$ & $0(0)$ \\
\hline 4th graders & 371 & $8(2.2)$ & $0(0)$ & $8(2.2)$ & $0(0)$ \\
\hline 5th graders & 370 & $6(1.6)$ & $4(1.1)$ & $5(1.4)$ & $1(0.3)$ \\
\hline 6 th graders & 366 & $8(2.2)$ & $3(0.8)$ & $5(1.4)$ & $1(0.3)$ \\
\hline 4th-6th graders & 1,107 & $22(2.0)$ & $7(0.6)$ & $18(1.6)$ & $2(0.2)$ \\
\hline 7th graders & 315 & $27(8.6)$ & $3(1.0)$ & $17(5.4)$ & $3(1.0)$ \\
\hline 8th graders & 336 & $17(5.1)$ & $10(3.0)$ & $19(5.7)$ & $3(0.9)$ \\
\hline 9th graders & 351 & $27(7.7)$ & $9(2.6)$ & $29(8.3)$ & $2(0.6)$ \\
\hline 7th-9th graders & 1,002 & $71(7.1)$ & $22(2.2)$ & $65(6.5)$ & $8(0.8)$ \\
\hline All girls & 3,221 & $98(3.0)$ & $29(0.9)$ & $83(2.6)$ & $10(0.3)$ \\
\hline
\end{tabular}

Europe (Hungary, Switzerland, Italy, Iceland, Poland), Asia (China, Hong Kong, India), and Africa (Uganda) showed an overall prevalence of approximately $3 \% .^{21)}$

\section{Management of pediatric hypertension}

\section{Aims}

The aims for managing pediatric hypertension are as follows: (1) prevention of organ damage due to hypertension; (2) appropriate diagnosis and treatment of pediatric secondary hypertension; and (3) improvement of pediatric essential hypertension by healthy lifestyle modification and prevention of progression to adult essential hypertension.

\section{Procedure for management of pediatric hypertension}

If the $\mathrm{BP}$ value is close to the criterion for pediatric hypertension, measurements should be made 2 or more times on different occasions. BP should be measured once a year when the BP values are within the normal range. Children and adolescents with a BP near the criterion should be educated on healthy lifestyle modifications and undergo BP measurements 
every 3 months. Pediatric hypertension is diagnosed when BP threshold values are exceeded on 3 or more occasions. Next, individuals with pediatric hypertension should be examined for the presence or absence of secondary hypertension. If secondary hypertension is present, the causative disease should be treated. If secondary hypertension is absent, thus confirming essential hypertension, healthy lifestyle modifications should be adopted for at least 3-6 months. Persistent pediatric hypertension despite nonpharmacological therapies involving healthy lifestyle modification is an indication for pharmacotherapy. ${ }^{11}$

\section{Healthy lifestyle modifications}

Important factors contributing to a healthy lifestyle include early bedtime, early rising, and eating breakfast. Salt restriction and increasing potassium intake represent important dietary treatments, similar to adults. Dietary treatments for obese children include restricting energy intake, adequate nutrient distribution, and correcting poor eating habits, such as overeating. Avoiding a sedentary lifestyle and limiting screen time is also important. Moderate exercise for $30-60$ minutes 3 to 5 times a week is recommended. ${ }^{1)}$

\section{Pharmacotherapy}

Pharmacotherapy is indicated for children with hypertension who meet the following criteria: persistent hypertension despite nonpharmacological therapies involving lifestyle modifications for 3-6 months; symptomatic hypertension; secondary hypertension requiring pharmacotherapy; concomitant development of target organ damage evidenced by proteinuria, microalbuminuria (>30 mg/g creatinine), and cardiac hypertrophy with $\mathrm{CKD}$; and the presence of diabetes mellitus.

The following antihypertensive drugs have been used: enalapril and lisinopril as angiotensin-converting enzyme inhibitors (ACEIs); valsartan and candesartan as angiotensin II receptor blockers (ARBs); amlodipine as a calcium channel blocker; propranolol as a beta-blocker; and trichlormethiazide, hydrochlorothiazide, and benzylhydrochlorothiazide as diuretics. ACEIs and ARBs are recommended for the treatment of CKD and left ventricular hypertrophy. ${ }^{1)}$

\section{Conclusion}

The prevalence of pediatric hypertension is much lower than that of adults. However, screening for pediatric hypertension is very important for identifying severe secondary hypertension and preventing the future development of adult essential hypertension. Thus, BP should be routinely measured in children and adolescents.

\section{Footnotes}

Conflicts of interest: No potential conflict of interest relevant to this article was reported.

Funding: This work was supported by JSPS KAKENHI grants (nos. 17K01867 and 20K11653).

Acknowledgments: I wish to express my sincere thanks to Prof. Makoto Uchiyama and Prof. Akihiko Saitoh in the Department of Pediatrics at Niigata University School of Medicine for their guidance. I am grateful to the Education Committee of Mitsuke City and Drs. Naoshi Hashimoto, Takuya Kawasaki, Hisashi Yamazaki, Masahiro Nishina, Keisuke Nagasaki, Kazuhiro Kameda, Makoto Hiura, Yukie Tanaka, Yohei Ogawa, and Hidetoshi Sato of the Department of Pediatrics at the Niigata University School of Medicine for their assistance with this study.

ORCID:

Toru Kikuchi @ https://orcid.org/0000-0001-8392-6148

\section{References}

1. Kikuchi T. Hypertension in children. In: The Japanese Society of Hypertension Committee for Guidelines for the Management of Hypertension. The Japanese Society of Hypertension Guidelines for the Management of Hypertension (JSH 2019). Hypertens Res 2019;42:1392-6.

2. Kikuchi T, Hashimoto N, Okugawa T, Uchiyama M. A study of the relation between blood pressure and body height in Japanese children. J Child Health 2000;54:405-8.

3. Kikuchi T, Nagasaki K, Ogawa Y, Abe Y, Hiura M, Tanaka Y, et al. A study of the tracking phenomenon of blood pressure and physique at 1 st graders to 9th graders, Mitsuke Study. Jpn J Pediatr Hypertens 2010;7:10-7.

4. Uchiyama M. Risk factors for the development of essential hypertension: long-term follow-up study in junior high school students in Niigata, Japan. J Hum Hypertens 1994;8:323-5.

5. Kawasaki T, Uezono K, Sanefuji M, Utsunomiya H, Fujino T, Kanaya S, et al. A 17-year follow-up study of hypertensive and normotensive male university students in Japan. Hypertens Res 2002;26:445-52.

6. Theodore RF, Broadbent J, Nagin D, Ambler A, Hogan S, Ramrakha S, et al. Childhood to early-midlife systolic blood pressure trajectories: early-life predictors, effect modifiers, and adult cardiovascular outcomes. Hypertension 2015;66:1108-15.

7. Nishina M, Kikuchi T, Yamazaki H, Kameda K, Hiura M, Uchiyama M. Relationship among systolic blood pressure, serum insulin and leptin, and visceral fat accumulation in obese children. Hypertens Res 2003;26:2818.

8. Lava SA, Bianchetti MG, Simonetti GD. Salt intake in children and its consequences on blood pressure. Pediatr Nephrol 2015;30:1389-96.

9. Tanaka S, Kaneko K, Ito Y, Uchiyama M. Epidemiological study by national questionnaire survey on underlying diseases in Japanese children with hypertension. Jpn J Pediatr Hypertens 2007;4:23-7.

10. Li AM, Au CT, Ng C, Lam HS, Ho CKW, Wing YK. A 4-year prospective follow-up study of childhood OSA and its association with BP. Chest 2014;145:1255-63.

11. Kikuchi T, Nagasaki K, Hiura M, Tanaka Y, Ogawa Y, Uchiyama M. The usefulness of blood pressure measurement in obese children. J Japan Soc Study Obesity 2005;11:69-73.

12. Gluckman PD, Hanson MA. Living with the past: evolution, development, and patterns of disease. Science 2004;305:1736.

13. Hashimoto N, Kawasaki T, Kikuchi T, Takahashi H, Uchiyama M. The relationship between the intrauterine environment and blood pressure in 3-year-old Japanese children. Acta Paediatr 1996;85:132-8.

14. Miura K, Nakagawa H, Tabata M, Morikawa Y, Nishijo M, Kagamimori 
S. Birth weight, childhood growth, and cardiovascular disease risk factors in Japanese aged 20 years. Am J Epidemiol 2001;153:783-9.

15. Abe Y, Kikuchi T, Nagasaki K, Hiura M, Tanaka Y, Ogawa Y, et al. Lower birth weight associated with current overweight status is related with the metabolic syndrome in obese Japanese children. Hypertens Res 2007; 30:627-34.

16. Hales CN, Barker DJ. The thrifty phenotype hypothesis. Br Med Bull 2001;60:5-20.

17. Zandi-Nejad K, Luyckx VA, Brenner BM. Adult hypertension and kidney disease: the role of fetal programming. Hypertension 2006;47:502-8.

18. Kikuchi T, Yamazaki H, Kameda K, Hiura M, Nishina M, Uchiyama $\mathrm{M}$. The effects on the blood pressure evaluation of school children as determined by the frequency of measurements. J Child Health 2002; 61:322-7.

19. Flynn JT, Kaelber DC, Baker-Smith CM, Blowey D, Carroll AE, Daniels SR, et al. Clinical practice guideline for screening and management of high blood pressure in children and adolescents. Pediatrics 2017;140: e20171904.

20. Xi B, Zhang T, Li S, Harville E, Bazzano L, He J, et al. Can pediatric hypertension criteria be simplified? A prediction analysis of subclinical cardiovascular outcomes from the Bogalusa Heart Study. Hypertension 2017;69:691-6.

21. Sun J, Steffen LM, Ma C, Liang Y, Xi B. Definition of pediatric hypertension: are blood pressure measurements on three separate occasions necessary? Hypertens Res 2017;40:496-503.

How to cite this article: Kikuchi T. Pediatric hypertension based on Japanese Society of Hypertension Guidelines (JSH 2019) with actual school blood pressure screening data in Japan. Clin Exp Pediatr 2022;65:283-90. https://doi.org/10.3345/cep. 2021.00920 